\title{
Eat, breathe, sleep with Osteogenesis Imperfecta
}

\author{
Antonella LoMauro ${ }^{1 *}$ (⿺辶) , Carlo Vittorio Landoni ${ }^{2}$, Paolo Fraschini ${ }^{3}$, Franco Molteni ${ }^{2}$, Andrea Aliverti ${ }^{1}$, \\ Simona Bertoli4 ${ }^{4,5}$ and Ramona De Amicis ${ }^{4}$
}

\begin{abstract}
Background: Although Osteogenesis Imperfecta (OI) affects the connective tissue causing extremely brittle bones with consequent skeletal deformities, it is important to go beyond bones. Indeed, the quality of life in Ol does not only depend on bones status, as OI might affect also other important functions. We have therefore implemented a multidisciplinary study to assess lung function, breathing pattern, sleep quality and nutritional status in 27 adult OI type III and IV patients (median age: 34.6 years; 19 women; 14 type III).

Results: According to nocturnal oxygen desaturation, two groups were identified: 13 patients with (OI_OSA, incidence: 48.2\%) and 14 without (no_OSA) obstructive sleep apnea. The former was characterized by higher spinal and ribcage deformity, by more restrictive lung function, by paradoxical thoracic breathing in supine position, by rapid and shallow breathing, by higher body mass index, by longer neck and waist circumferences; by higher abdominal volume and by greater percentage of body fat mass, particularly localized in the trunk.

The best predictor of OI_OSA was the negative value of the supine ribcage contribution to tidal volume, followed by the ratio between the neck and the waist circumferences with body height and the supine thoraco-abdominal volumes phase shift angle.

Conclusions: The pathophysiology of Ol ensued a dangerous vicious circle, in which breathing, sleep and nutritional status are tightly linked, and they might all end up in negatively affecting the quality of life. The vicious circle is fed by some intrinsic characteristics of the disease (thoracic, cranial and mandibular deformities) and some bad daily habits of the patients (i.e. physical inactivity and low dietary quality). The former impacts on restricting the respiratory function, the latter makes Olers more prone to experience overweight or obesity. The main consequence is a high incidence of obstructive sleep apnea, which remains an underdiagnosed disorder in individuals with severe OI who are obese, with a neck to height ratio over than $31.6 \%$, and characterized by paradoxical breathing in supine position. A multidisciplinary approach, including evaluations of breathing, sleep and nutrition, is required to better manage the disease and fulfil the maximizing well-being of Ol patients.
\end{abstract}

Keywords: Osteogenesis Imperfecta, Spirometry, Opto-electronic plethysmography, Obstructive sleep apnea, Noninvasive ventilation, Fat mass, Body composition, Mediterranean diet, Scoliosis, AHI index

*Correspondence: antonella.lomauro@polimi.it

1 Dipartimento di Elettronica, Informazione e Bioingegneria, Politecnico di Milano, Piazza Leonardo Da Vinci, 20133 Milano, Italy

Full list of author information is available at the end of the article

\section{Background}

Osteogenesis Imperfecta (OI) is a group of rare disorders occurring in 1 in 15,000 to 20,000 births [1]. It affects the connective tissue causing extremely fragile bones that break or fracture easily (brittle bones) and often without apparent cause [2]. There are four classical OI types according to severity based on clinical and original author(s) and the source, provide a link to the Creative Commons licence, and indicate if changes were made. The images or other third party material in this article are included in the article's Creative Commons licence, unless indicated otherwise in a credit line to the material. If material is not included in the article's Creative Commons licence and your intended use is not permitted by statutory regulation or exceeds the permitted use, you will need to obtain permission directly from the copyright holder. To view a copy of this licence, visit http://creativecommons.org/licenses/by/4.0/. The Creative Commons Public Domain Dedication waiver (http://creativeco mmons.org/publicdomain/zero/1.0/) applies to the data made available in this article, unless otherwise stated in a credit line to the data. 
radiological evaluation. Type III is the most severe form compatible with life with severely bone deformities and short height, while type I and IV are mild forms with moderate or less severe bone deformities [3].

The prevention, treatment and monitor of the respiratory function are important factors for prognosis in OI, as respiratory failure is the leading cause of death in these patients $[4,5]$. For a respiratory point of view, OI is classified as a restrictive disease [6-9]. The two main factors predisposing to restricted respiratory problems in severe OI are severe kyphoscoliosis and structural modifications of the ribcage, with the most important effect being thoraco-abdominal asynchrony with thoracic paradoxical inward movement $[8,10,11]$. Because in the most severe OI form these alterations systematically occur at rest in supine position, we wonder if they may negatively affect sleep. Indeed, obstructive sleep apnea is recently shown to easily be left as an undetected disorder in OIers $[12,13]$. This is a crucial problem, since sleep disordered breathing causes, among others, excessive daytime somnolence with negative effects on attention and vigilance, therefore reducing the quality of life.

In otherwise healthy patients, both respiratory function and sleep depend on nutritional status. Obesity induces restrictive respiratory pattern while promoting obstructive apneas during sleep [14-16]. Individuals with OI may experience overweight or even obesity secondary to physical inactivity, small body size and, possibly, inappropriate caloric intake and dietary quality $[17,18]$. However, information on the nutritional status, body composition, and dietary habits of these patients is scarce, particularly in adult population. Collagen abnormalities, typical of OI, seem to imply also fat and fat free mass [19]. On the other hand, alterations in body composition is shown to be a strong risk factor for bone fractures in OI patients [18]. Particularly, truncal and abdominal fat mass is inversely related to bone mineral density [20] and sleep apnea because of the secretion of inflammatory cytokines causing increased bone resorption [21] and fat deposit in upper airway lumen and muscles [22]. Moreover, decreased mobility improves loss of lean mass, especially in terms of muscle mass, with increase of daily fatigue and exhaustion, therefore limiting daily activity, increasing obesity risk and ensuring a vicious circle [23]. In this scenario, a balanced diet rich in multifunctional nutrients (especially vegetables proteins, vitamins B, D and E, omega-3 fatty acids, oleic acid, selenium, calcium and polyphenolic compounds) with antioxidant and anti-inflammatory effects, as the Mediterranean pattern, could be recommended not only to improve body composition but also to potentiate pharmacologic treatment and physical activity [18].
Our main goal was to verify if the pathophysiology of OI in adult patients ensued a dangerous vicious circle, in which breathe, sleep and nutrition are tightly linked. We therefore implemented a multidisciplinary and multicentre study to assess lung function, breathing pattern, sleep quality and nutritional status on a group of OI patients.

\section{Methods}

The study was conducted according to the statement of the Declaration of Helsinki and approved by the Ethical Board Committee of Valduce Hospital - Villa Beretta Rehabilitation Centre, Lecco, Italy.

\section{Patients}

Patients were firstly enrolled among the members of As.It.O.I., the Italian Association of Osteogenesis Imperfecta. As.It.O.I., by posting an announcement of the association Facebook page.

Inclusion criteria were: confirmed diagnosis of OI type III and IV, stable condition, absence of severe cardiorespiratory pathologies, willingness to participate to the study and to travel to Milan for the tests. Informed consent was obtained from all study subjects or parents.

\section{Quality of life questionnaire}

All patients filled in an Osteogenesis Imperfecta specific Quality of Life Questionnaire (OIQoL) [24, 25] comprising 33 questions grouped in six main themes (being safe and careful, reduced function, pain, fear, fatigue, independence). Each question was given a score ranging from 0 (worst scenario) to 4 (best scenario). For each theme, a global score was assigned as the mean of the corresponding questions.

\section{Spinal and ribcage deformity}

Thoracic scoliosis was assessed through standard anteroposterior and lateral radiographic views of the entire spine and quantified using the Cobb method $[26,27]$.

The angle subtended at the sternal level on the transversal plane was computed to quantitatively describe the geometrical deformity of the ribcage, as previously described [8].

The spinal and ribcage deformity were combined by computing the mean value among the transversal and sagittal sternal angles and the Cobb angles of the thoracic and lumbar scoliosis.

\section{Nocturnal oxygen saturation}

Median and nadir nocturnal oxygen saturation $\left(\mathrm{SpO}_{2}\right)$ was measured using a digital pulse oximeter (Nonin, 8500 digital pulse oximeter Quitman, TX). The number of apnoea and hypopnea events per hour of sleep (AHI index) as well as the number of times per hour of sleep 
of oxygen desaturation (ODI index) were calculated. OSA was diagnosed as mild when $5 \leq \mathrm{AHI}<15$; moderate when $15 \leq \mathrm{AHI}<30$; severe when $\mathrm{AHI} \geq 30$ [28].

\section{Lung function and breathing pattern at rest}

Measurement of forced vital capacity (FVC) and forced expiratory volume in $1 \mathrm{~s}\left(\mathrm{FEV}_{1}\right)$ were assessed through spirometry; while total lung capacity (TLC) through the nitrogen washout technique (Vmax series 22, SensorMedics, Yorba Linda, CA).

Accurate assessment of ventilatory and thoracoabdominal pattern during spontaneous quiet breathing was assessed by opto-electronic plethysmography (OEP System; BTS, Milan, Italy) in both seated and supine position (Fig. 1). Breathing frequency, tidal volume, minute ventilation (i.e. the product of the two), rapid and shallow breathing index (i.e. the ratio between breathing frequency and tidal volume), ribcage contribution to tidal volume $\left(\Delta \mathrm{V}_{\mathrm{RC}}\right)$ and thoraco-abdominal phase shift angle were computed on an average breath of at least $45 \mathrm{~s}$ of spontaneous breathing. The abdominal volume at end expiration was also computed and expressed as percentage of total chest wall volume.

Because the output of OEP is the position of passive reflective markers put according to anatomical points, the trunk height was calculated as the distance between the marker at the sternoclavicular joint and the marker below the naval at the level of the iliac crest.

\section{Nutritional status}

\section{Anthropometric measurements}

Anthropometric measurements were taken by the same operator, according to conventional criteria and measuring procedures [29]. Body weight (BW, kg) and body height $(\mathrm{BH}, \mathrm{cm})$ were measured to the nearest $0.1 \mathrm{~kg}$ and $0.5 \mathrm{~cm}$, respectively. In subjects able to maintain the upright position, BW was measured on a beam balance scale and $\mathrm{BH}$ was measured with a stadiometer; in nonambulant subjects unable to maintain the upright position, BW was measured using a digital wheelchair scale and $\mathrm{BH}$ was obtained measuring the supine length. BMI was calculated as $\mathrm{BW}(\mathrm{kg}) / \mathrm{BH}^{2}\left(\mathrm{~m}^{2}\right)$.
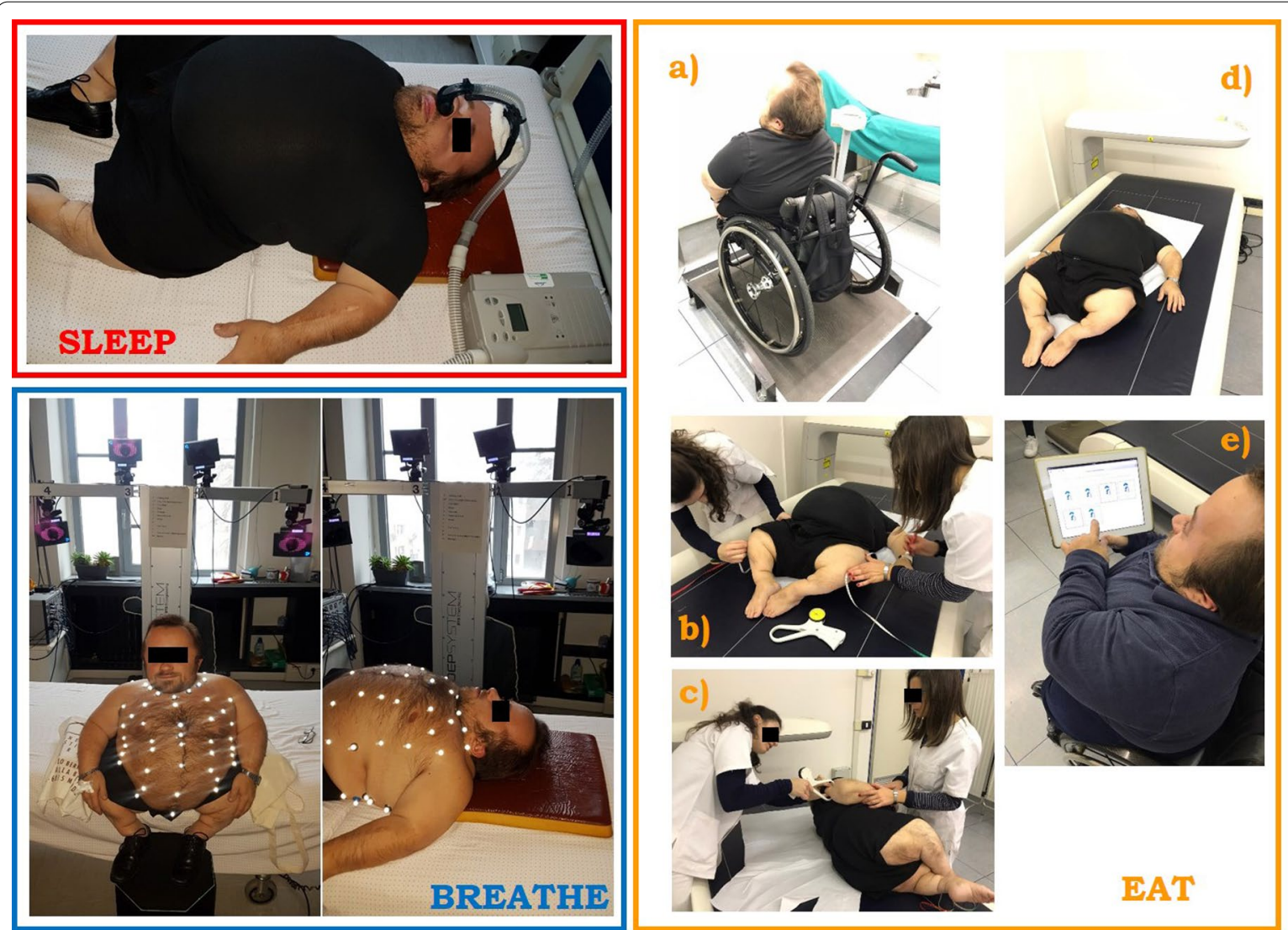

Fig. 1 Protocol of measurement: sleep study in a patient already using nocturnal non-invasive mechanical ventilation (SLEEP, red); breathing pattern assessment through opto-electronic plethysmography (BREATHE, blue) and weight, height, anthropometric measurements, MED questionnaire (EAT, yellow) 
Waist circumferences were measured midway between the lower rib margin and the superior anterior iliac spine using a horizontally applied non-stretch tape, and it was measured to the nearest $0.5 \mathrm{~cm}$.

\section{Dual-energy X-ray absorptiometry}

DEXA scans (iDXA; General Electric, formerly Lunar Corp., Madison, WI) were used to obtain the body composition. DEXA provides measurements of soft tissue and bone for the total body and the sub regions (namely arm, trunk, leg) including fat mass (FM), lean body mass (LM) and bone mineral content (BMC). The fat mass percentage (FM\%) was obtained as the ratio between total body fat mass and total body mass (fat + lean mass + bone mass of total body) multiplied for 100 . The fat free mass (FFM) was calculated by adding BMC to LM. Fat mass (FMI) and lean mass indexes (LMI) were calculated by dividing FM and LM by the squared height, respectively. To investigate the proportion between LM and FM their ratio was also calculated.

The trunk region starts at the inferior edge of the chin and the lower borders intersect the middle of the femoral necks without touching the brim of the pelvis. It includes the neck, chest, abdominal and pelvic areas [30].

The scanning was done with patients lying supine on the table, their feet in a neutral position and arms resting along their sides, palms facing upwards. The DEXA scans, performed by well-trained and certified research staff, were all done using one device and the same software (enCORE, 2010), for an average measuring time of $10 \mathrm{~min}$. The exposure to radiation was $<7 \mathrm{mSv}$. Daily quality-assurance was tested according to manufacturer directions. The DEXA scans were analysed using a custom-made software that allows body composition measurements in close relation to metal orthopaedic implants, by exclusion of no-osseous pixels.

\section{Adherence to the Mediterranean diet and eating behaviour}

Adherence to the traditional Mediterranean diet was assessed using a validated 14-item questionnaire [31]. The guidelines set out by the Prevención con Dieta Mediterránea (PREDIMED) study group (www.predimed.es) with some adaptation already employed in previous studies were used to obtain the Mediterranean score (MED score) [32, 33]. One point was attributed for each of the following: (1) olive oil as the main cooking fat; (2) olive oil $\geq 4$ tablespoons/day; (3) vegetables $>2$ servings/day (or $\geq 1$ portion raw or salad) [31]; (4) fruit $\geq 3$ servings/ day; (5) red or processed meat $<1$ serving/day; (6) butter or cream or margarine $<1 /$ day; (7) sugar-sweetened beverages $<1 /$ day; (8) wine $\geq 3$ glasses/week; (9) legumes $\geq 3$ servings/week; (10) fish/seafood $\geq 3$ servings/week; (11) commercial sweets and confectionery<3/week; (12) nuts $\geq 1$ /week; (13) white more than red meats (yes); and (14) use of sofrito $\geq 2$ /week. Participants with a MED score $\geq 9$ points were considered as complying with a dietary pattern in accordance with the Mediterranean diet [31].

Eating behaviour was tested through the Binge Eating Scale (BES), a 16-item self-report questionnaire designed to capture the behavioural, the cognitive and the emotional features of regular objective compulsive overeating [34].

\section{Statistical analysis}

Mann-Whitney rank sum test was used to assess differences between the two groups, which resulted non-normal distributed according to Kolmogorov-Smirnov test, with OSA status as independent factor (SigmaStat version 11.0; Systat Software, San Jose, Calif., USA).

Significance was set as $p<0.05$. Data in the results section of the text are reported as median value (25th-75th percentiles).

For all the parameters that resulted significantly different between the two groups of patients, the receiver operating characteristic (ROC) curve was computed to illustrate their diagnostic ability in our binary classifier system.

The area under the ROC curve (AUC) was also calculated. AUC is an evaluation metrics for checking any classification model's performance. The higher AUC, the better the model is at distinguishing between patients with OSA and no-OSA. AUC is considered excellent for values between 0.9 and 1 , good between 0.8 and 0.9 , fair between 0.7 and 0.8 , poor between 0.6 and 0.7 and failed between 0.5 and $0.6[35,36]$.

Finally, the threshold of each considered parameter, which corresponds to the optimal operating point of the ROC analysis, was also derived.

\section{Results}

Patients

Forty-five patients answered to the announcement willing to participate to the study, but 18 did not meet the inclusion criteria, with logistic and independent travelling to Milan being the principal impediment.

Twenty-seven OI patients (19 women; 14 type III $[3,37,38])$ were therefore recruited for this study [age: 34.6 (31.1-44.6) years; height: $1.24(1.0-1.4) \mathrm{m}$; weight: 46.8 (34.6-61.5) kg; BMI: $30.9(25.0-35.7) \mathrm{kg} / \mathrm{m}^{2}$; body fat mass: $39.3(34.7-47.3) \%$, the $51.5(45.1-61.2) \%$ of which located in the trunk, fat mass/fat free mass: 0.69 $(0.55-0.94)]$.

According to nocturnal oxygen desaturation, two groups were identified (Table 1): 13 patients with obstructive sleep apnoea (OI_OSA; 7 women; 10 type III; 9 wheelchair bound patients; 4 patients under nocturnal 
Table 1 Ol quality of life, thoracic deformity and nutritional status

\begin{tabular}{|c|c|c|c|c|c|c|c|}
\hline & \multicolumn{3}{|l|}{ no_OSA } & \multicolumn{3}{|l|}{ OI_OSA } & \multirow[t]{2}{*}{$P$ value } \\
\hline & Median & 25th $p$ & 75th $p$ & Median & 25th $p$ & 75th $p$ & \\
\hline Age (years) & 32.7 & 17.4 & 44.4 & 39.3 & 34.3 & 49.0 & 0.094 \\
\hline \multicolumn{8}{|l|}{ Ol quality of life } \\
\hline Safety (/4) & 3.50 & 3.38 & 3.50 & 3.50 & 3.25 & 3.50 & 0.945 \\
\hline Fatigue (/4) & 3.50 & 3.00 & 3.50 & 3.00 & 3.00 & 3.50 & 0.345 \\
\hline Reduced function (/4) & 3.50 & 3.00 & 3.50 & 3.50 & 3.00 & 3.50 & 0.892 \\
\hline Pain (/4) & 3.00 & 2.50 & 3.50 & 3.00 & 2.50 & 3.50 & 0.653 \\
\hline Fear (/4) & 3.50 & 3.38 & 3.50 & 3.50 & 3.00 & 3.50 & 0.710 \\
\hline Independence (/4) & 3.50 & 3.50 & 4.00 & 3.50 & 3.00 & 4.00 & 0.575 \\
\hline \multicolumn{8}{|l|}{ Thoracic deformity } \\
\hline Transversal sternal angle $\left(^{\circ}\right)$ & 164.8 & 159.5 & 173.4 & 162.9 & 155.0 & 171.4 & 0.250 \\
\hline Sagittal sternal angle $\left(^{\circ}\right)$ & 165.8 & 163.9 & 172.4 & 169.0 & 159.0 & 176.8 & 0.547 \\
\hline Thoracic scoliosis (Cobb angle) & 30.0 & 20.0 & 30.0 & 35.0 & 30.0 & 40.0 & 0.055 \\
\hline Lumbar scoliosis (Cobb angle) & 30.0 & 20.0 & 32.5 & 35.0 & 30.0 & 40.0 & 0.048 \\
\hline \multicolumn{8}{|l|}{ Nutritional status } \\
\hline Weight (kg) & 46.1 & 32.9 & 58.0 & 47.6 & 34.6 & 65.0 & 0.789 \\
\hline Height (m) & 1.36 & 1.13 & 1.42 & 1.16 & 1.01 & 1.28 & 0.132 \\
\hline Neck circumference (cm) & 34.5 & 32.3 & 35.5 & 38.8 & 38.0 & 41.0 & 0.010 \\
\hline Waist circumference (cm) & 75.3 & 71.1 & 86.7 & 100.0 & 82.8 & 110.8 & 0.039 \\
\hline Abdominal volume (\%chest wall) & 25.8 & 24.7 & 33.3 & 35.3 & 33.3 & 42.2 & 0.013 \\
\hline Fat mass/fat free mass & 0.62 & 0.49 & 0.74 & 0.89 & 0.61 & 1.14 & 0.056 \\
\hline $\operatorname{LMI}\left(\mathrm{kg} / \mathrm{m}^{2}\right)$ & 15.0 & 14.2 & 16.4 & 16.9 & 15.5 & 17.8 & 0.064 \\
\hline $\mathrm{FMI}\left(\mathrm{kg} / \mathrm{m}^{2}\right)$ & 8.4 & 7.6 & 13.0 & 14.8 & 10.7 & 21.9 & 0.030 \\
\hline $\mathrm{LMI}_{\mathrm{TR}}\left(\mathrm{kg} / \mathrm{m}^{2}\right)$ & 163.9 & 148.5 & 187.8 & 198.8 & 171.2 & 218.4 & 0.036 \\
\hline $\mathrm{FMI}_{\mathrm{TR}}\left(\mathrm{kg} / \mathrm{m}^{2}\right)$ & 96.0 & 68.0 & 148.9 & 176.1 & 121.6 & 282.8 & 0.033 \\
\hline MED score & 6.00 & 5.00 & 6.75 & 6.00 & 5.00 & 7.00 & 0.564 \\
\hline
\end{tabular}

non-invasive mechanical ventilation for a former diagnosis of obstructive sleep apnoea) and 14 patients without obstructive sleep apnoea (no_OSA; 12 women; 4 type III; 11 ambulant patients).

\section{Quality of life}

According to the OI Quality of Life questionnaire, no differences were found between the two groups in terms of safety, reduced function, pain, fear, fatigue and independence (Table 1).

\section{Spinal and ribcage deformity}

While sternal angles were similar between the two groups, both thoracic and lumbar Cobb angles were significantly higher in OI_OSA patients (Table 1). The mean values of sternal angles, thoracic and lumbar Cobb angles were significantly higher in OI_OSA $\left(101,100^{\circ}-104^{\circ}\right)$ compared to no_OSA $\left(95,92^{\circ}-101^{\circ}, p=0.025\right)$ patients.

\section{Sleep}

By definition, OI_OSA patients were characterized by significantly higher AHI and oxygen desaturation index (ODI), and by significantly lower mean and nadir nocturnal oxygen saturation (Fig. 2).

\section{Breathe}

OI_OSA patients were characterized by lower forced vital capacity, forced expired volume in one second and total lung capacity when expressed as absolute and percentage value (Fig. 3). Despite similar ventilatory pattern between the two groups in supine position, OI_OSA patients breathed with a systematic inward inspiratory paradoxical movement of the ribcage, leading to almost paradoxical thoraco-abdominal breathing with the phase shift angle approaching $180^{\circ}$ (Fig. 4). In seated position, OI_OSA patients breathed with higher rapid and shallow breathing index, because of lower tidal volume, due to reduced ribcage contribution, with consequent higher thoraco-abdominal phase shift angle (Fig. 5). 


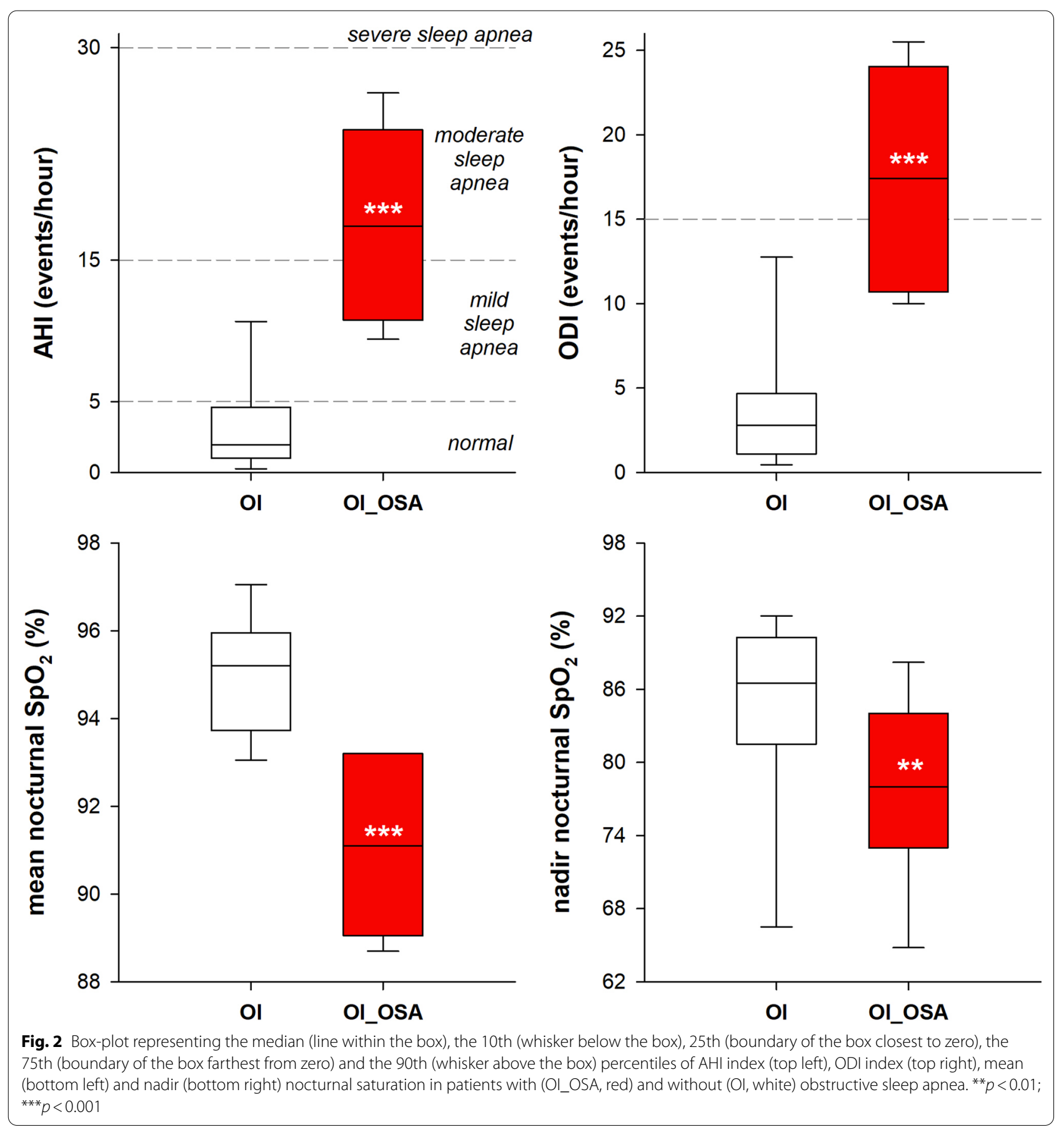

(See figure on next page.)

Fig. 3 Box-plot representing the median (line within the box), the 10th (whisker below the box), 25th (boundary of the box closest to zero), the 75th (boundary of the box farthest from zero) and the 90th (whisker above the box) percentiles of forced vital capacity (top), forced expiratory volume in the first second (middle) and total lung capacity (bottom) in patients with (OI_OSA, blue) and without (OI, white) obstructive sleep apnea. Data are expressed both as litres (left panels) and as percentage of the predicted values (right panels). ${ }^{*} p<0.05 ;{ }^{* *} p<0.01 ;{ }^{* * *} p<0.001$ 

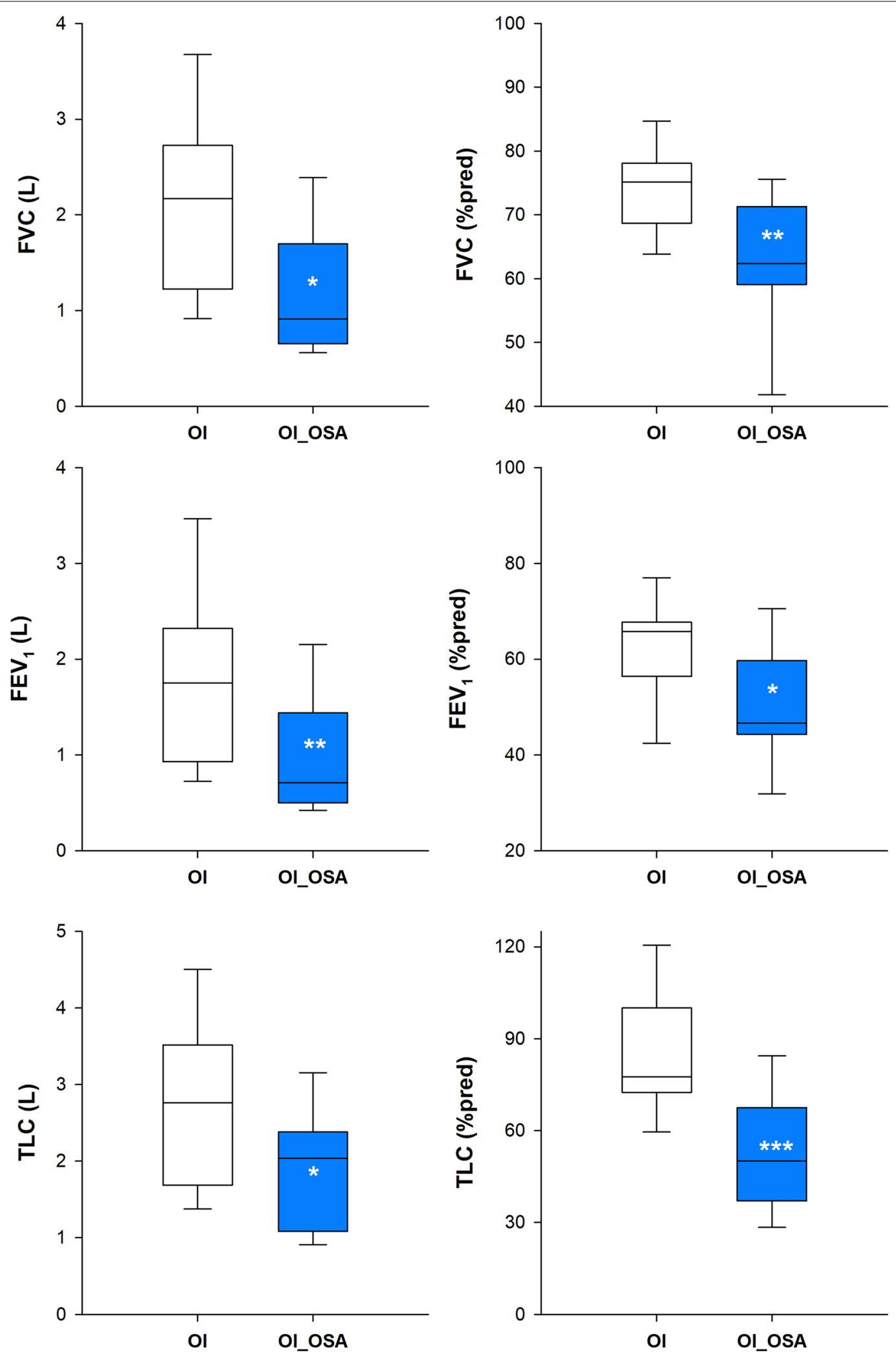

Fig. 3 (See legend on previous page.) 


\section{Eat}

Although weight and height were similar between the two groups (Table 1), body mass index was significantly higher in OI_OSA (60\% of obesity in OI_OSA vs 46\% in no_OSA; Fig. 6). In these patients, neck and waist circumferences were significantly longer when expressed both as absolute value (Table 1) and normalized according to body height (Fig. 6). Similarly, abdominal volume was higher in OI_OSA when expressed as percentage of total chest wall volume (Table 1). They also presented greater percentage of body fat mass, particularly localized in the trunk (Fig. 6), and, consequently, lower lean mass index.

Concerning dietary habits, 85\% of OI_OSA showed a lower dietary quality (MED score $<9$ ) compared to $71 \%$ of no_OSA. In general, $78 \%$ of all participants reported a low consumption of wholesome foods, such as fish, fruit, vegetables, legumes, nuts, and a higher tendency to the consumption of noxious foods, such as sugary drinks, red meat, and confectionery.

We did not report data on eating behaviour, since only three patients (11\%) answered the BES questionnaire.

\section{Receiver operating characteristic (ROC) curve}

Table 2 reports the area under the receiver operating characteristic (ROC) curve (AUC) and the threshold corresponding to the optimal operating point of the ROC analysis therefore relieving the best predictors of OSA in OI.

A part form AHI and ODI, a negative value of the supine ribcage contribution to tidal volume resulted to be the best predictor of OSA in OI. The other best predictors were the ratio between the neck and the waist circumferences with body height and the supine thoracoabdominal phase shift angle.

\section{Discussion}

The pathophysiology of OI ensued a dangerous vicious circle, in which breathing, sleep and nutritional status are tightly linked, and they might all end up in negatively affecting the quality of life (Fig. 7). Obstructive sleep apnoea occurred in the $48.2 \%$ of our study population, the $70 \%$ of which was a new diagnosis because of the screening and not because of patients' awareness of the problem. OSA was prevalent in subtype III obese patients who were characterized by more restrictive lung pattern, thoracic paradoxical movement in supine position and fat predominantly located around the neck and in the abdomen. Paradoxical breathing and neck circumference were the best discriminators for OI patients experiencing OSA.

OSA is a severe public health problem for the general population. It may increase the risks for hypertension, cardiovascular events, cerebrovascular accidents as well as for motor vehicle accidents and awakening headache [39]. OSA ultimately impacts on work performance [40] and depresses the quality of life. OSA risks tend to be underdiagnosed in OIers, although they frequently report fatigue and sleep disturbances [41]. Indeed, the incidence of OSA that we found in our population was very high, with the majority of OSA patients not being aware of the problem, as confirmed by the quality of life questionnaire. Our incidence was similar to that already found in another OI population [12], similar to the general obese population $(\sim 45 \%)$ and higher than the general population $(\sim 25 \%)$ [42].

However, OIers experiencing OSA are not "just" obese patients with OSA. OI patients are also characterized by a progressively severely reduced level of mobility of the thorax due to the fragility and the deformation not only of the bones, but also of the ligamentous and articular structures. For this reason, these patients deserve dedicated studies, while extrapolating the results from general and/or paediatric OI populations risks to underestimate the problem. In addition to the altered ribcage structure, OI patients might also experience altered gas exchange because of an intrinsic deficit of the collagen in the lung tissue [43]. The quality of sleep is strongly correlated with pulmonary function and breathing pattern and they could all depend on body weight. In addition, severe kyphoscoliosis and structural modifications of the ribcage (namely, pectus carinatum, horizontal and brittle ribs) are two typical OI characteristic that represent two main factors predisposing to respiratory problems, particularly in the most severe form. The former limits thoracic movements and lung expansion, the latter has important consequences on ribcage respiratory function. We believe that this interaction is mediated more by the combination of spinal and ribcage deformities rather than by the single one. Indeed, we have previously shown

(See figure on next page.)

Fig. 4 Box-plot representing the median (line within the box), the 10th (whisker below the box), 25th (boundary of the box closest to zero), the 75th (boundary of the box farthest from zero) and the 90th (whisker above the box) percentiles of minute ventilation (top left), rapid and shallow breathing index (top right), breathing frequency (middle left), tidal volume (middle right), pulmonary ribcage percentage contribution to tidal volume (bottom left) and thoraco-abdominal phase shift angle (bottom right) at rest in supine position in patients with (OI_OSA, blue) and without (Ol, white) obstructive sleep apnea. ${ }^{*} p<0.05$; ${ }^{* * *} p<0.001$ 

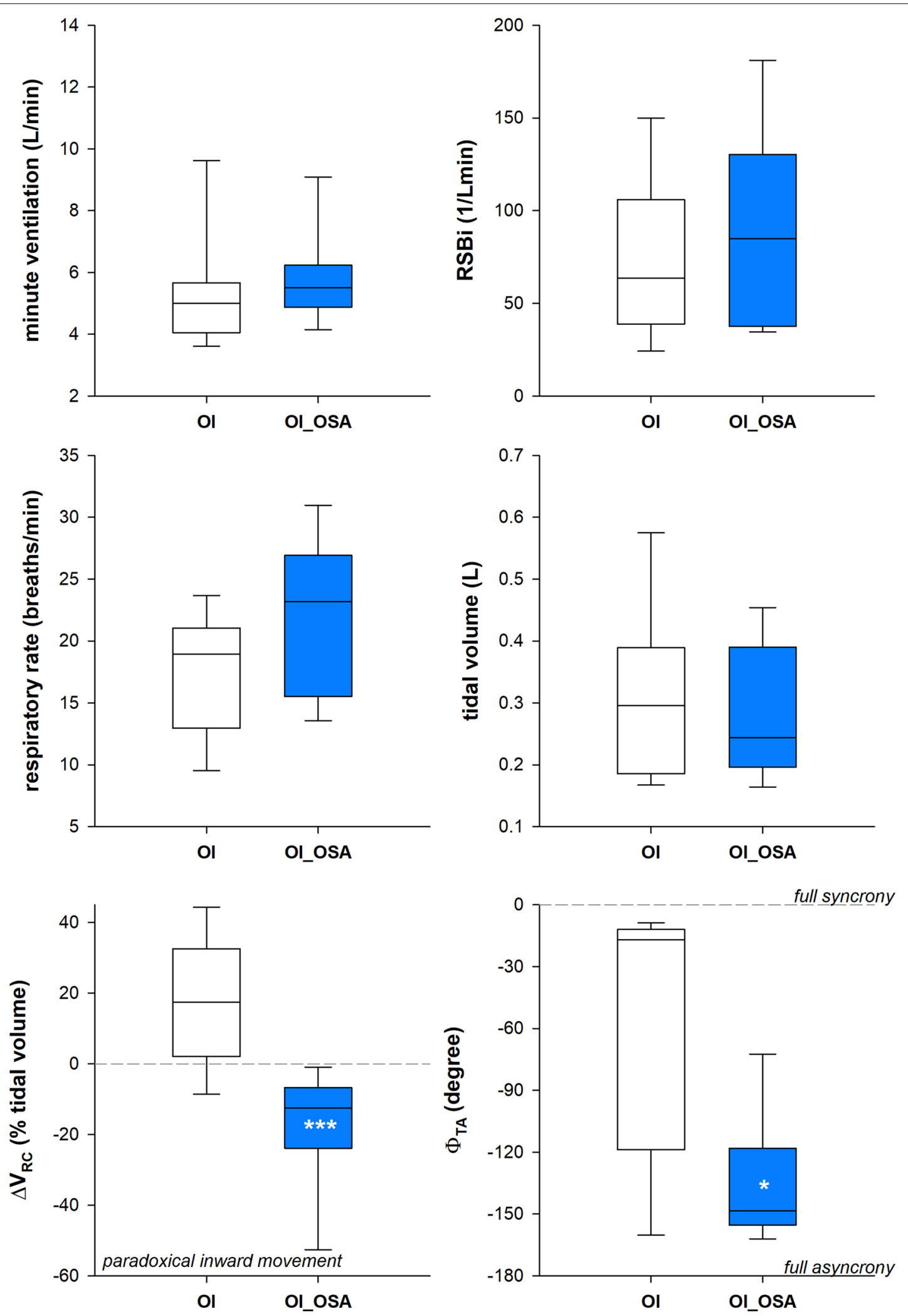

Fig. 4 (See legend on previous page.) 
that the altered breathing pattern in severe OI worsens with age as a consequence of the combination between the congenital pectus carinatum and spinal deformity that starts in later childhood to develop thereafter [10]. The results of the present study seem to go towards this direction, with the combining index of deformity significantly being higher in OSA group. These patients were characterized by a more severe restricted spirometric pattern and by thoraco-abdominal asynchrony with paradoxical inward movement of the ribcage during spontaneous breathing at rest particularly in supine position.

Besides thoracic deformities, nutritional status played an additional role that worsened this scenario. Significantly higher BMI, body fat mass, trunk fat mass, neck and waist circumferences as well as abdominal volume characterized adult Olers suffering from sleep apnoea. These results are in line with what previously found in children with OI [44]. In that study, the authors conclude that symptoms suggesting obstructive sleep disorders should be searched especially in children with compromised autonomy, high BMI, trunk deformations, and severe OI type [44].

The mechanical effect of the excessive adipose tissue located around the neck and the abdomen makes: (1) lung capacities further reduce; (2) chest wall compliance further decrease; (3) work of breathing further increase; (4) oxygen cost of breathing increase; (5) central respiratory drive reduce; (6) expiratory flow limitation increase; (7) inspiratory muscle strength decrease and (8) upper airways obstruction increase [14-16].

Olers are more prone to experience overweight or even obesity secondary to physical inactivity [45], small body size and inappropriate dietary habits [18, 46, 47]. This happens not only in paediatric patients [19], but also in adulthood as shown in this study. Body composition is anecdotally shown to be a strong risk factor for bone fractures in OI patients. Fat negatively affects bone physiology, while poor muscle mass and strength correlate with incremental risk of fractures, but also with daily fatigue and exhaustion, limiting daily activity $[18,20,21]$.

In order to act on this vicious circle of "eat, breathe and sleep in OI", a multidisciplinary approach is required to better understand and manage the disease and fulfil the maximizing well-being of OI patients. This approach may include the use of nocturnal non-invasive mechanical ventilation (nNIV) and/or the onset of a controlled dietary regimen.

We can speculate that the paradoxical inward movement of the ribcage together with the rapid and shallow breathing pattern promote pulmonary micro-atelectasis in OSA patients that could benefit by nNIV. nNIV is able to overcome upper airways obstruction during sleep, to reverse thoraco-abdominal asynchrony (as shown in Fig. 8) and therefore to recruit the lungs. In this way, nNIV prevents nocturnal hypoventilation and lung atelectasis. However, these are short-lived effects as nNIV is effective only during use, as indicated by the reappearance of the paradoxical motion immediately after the switching off of the ventilator in Fig. 8.

Because our patients showed low dietary quality, in terms of reduced adherence to the Mediterranean diet with low consumption of wholesome foods and higher consumption of noxious foods and confectionery, we believe, and therefore hypothesise, that an adequate dietary intake may break or at least ameliorate the vicious circle. The diet of these patients should include nutrients related to bone health, such as vegetables proteins, vitamins $\mathrm{B}, \mathrm{D}$ and $\mathrm{E}$, omega-3 fatty acids, oleic acid, selenium, calcium and polyphenolic compounds. The improvement of body composition (i.e. reduction of fat body mass with concomitant increase of lean body mass), as expected by a Mediterranean dietary pattern [48], may have long-lasting ameliorative effects on the quality of life in OI. These comprise: (1) decreasing body weight, truncal and abdominal fat; (2) supplying the adequate energy and micronutrients involved in bone metabolism; (3) reducing the incidence of nocturnal obstructive apnoea [49]; (4) reducing the burden on the thorax while breathing; (5) potentiating pharmacologic therapy (vitamin D and calcium supplement and/or bisphosphonate therapy) and (6) improving physical activity and mobility, particularly during wheelchair transfer.

It is important to reverse this trend, since a high frequency of apnoea during sleep may interfere with restorative sleep that it is known to contribute to negative consequences to health and quality of life. In addition, because of the recurrent fractures, severe OI patients are used to experience pain and fatigue since childhood and therefore they may develop higher level of tolerance, as indicated by the paradoxically good scores of the quality of life questionnaire. Indeed, these answers

(See figure on next page.)

Fig. 5 Box-plot representing the median (line within the box), the 10th (whisker below the box), 25th (boundary of the box closest to zero), the 75th (boundary of the box farthest from zero) and the 90th (whisker above the box) percentiles of minute ventilation (top left), rapid and shallow breathing index (top right), breathing frequency (middle left), tidal volume (middle right), pulmonary ribcage percentage contribution to tidal volume (bottom left) and thoraco-abdominal phase shift angle (bottom right) at rest in seated position in patients with (OI_OSA, blue) and without $\left(\mathrm{Ol}\right.$, white) obstructive sleep apnea. ${ }^{*} p<0.05 ;{ }^{* *} p<0.01$ 

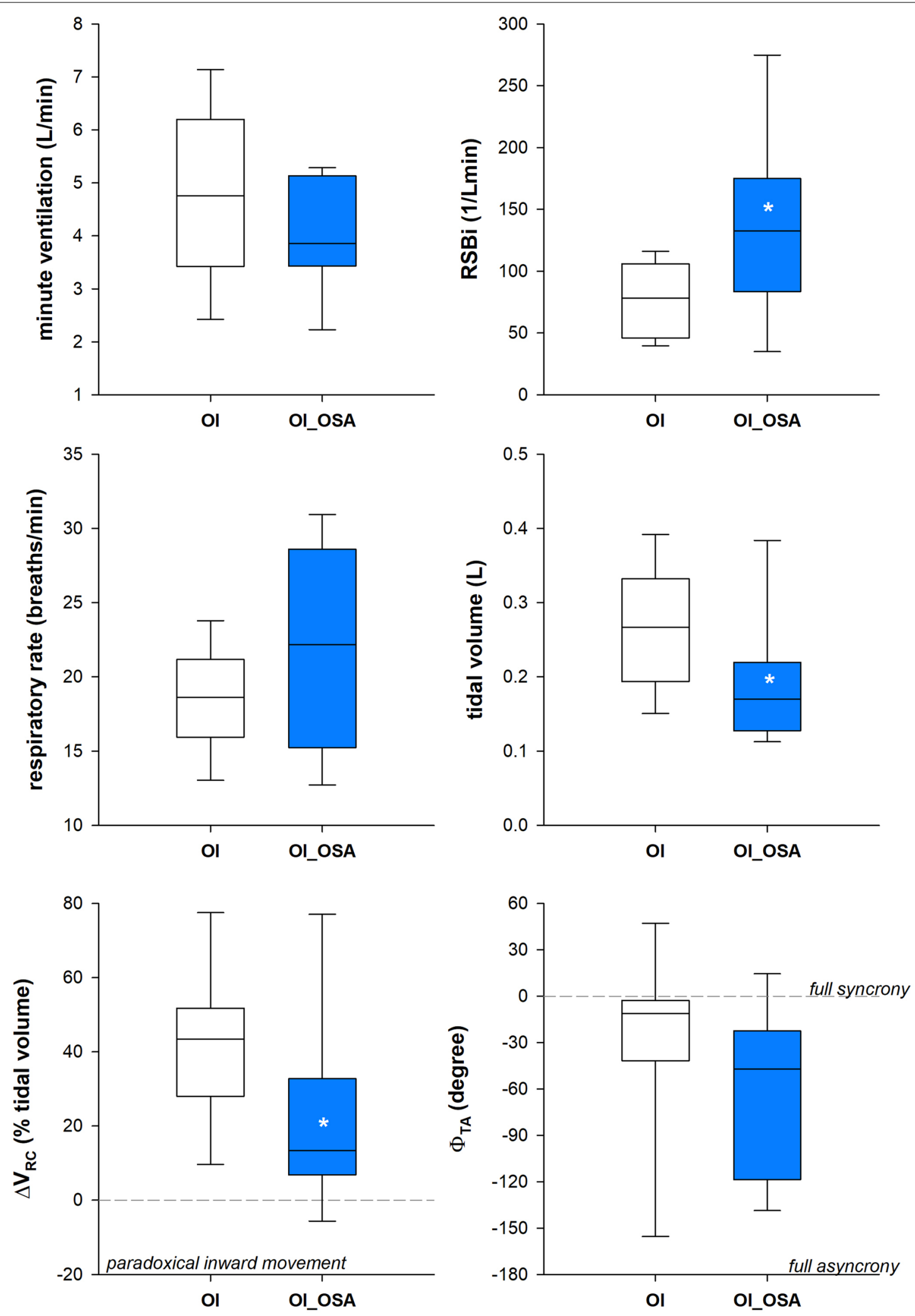

Fig. 5 (See legend on previous page.) 

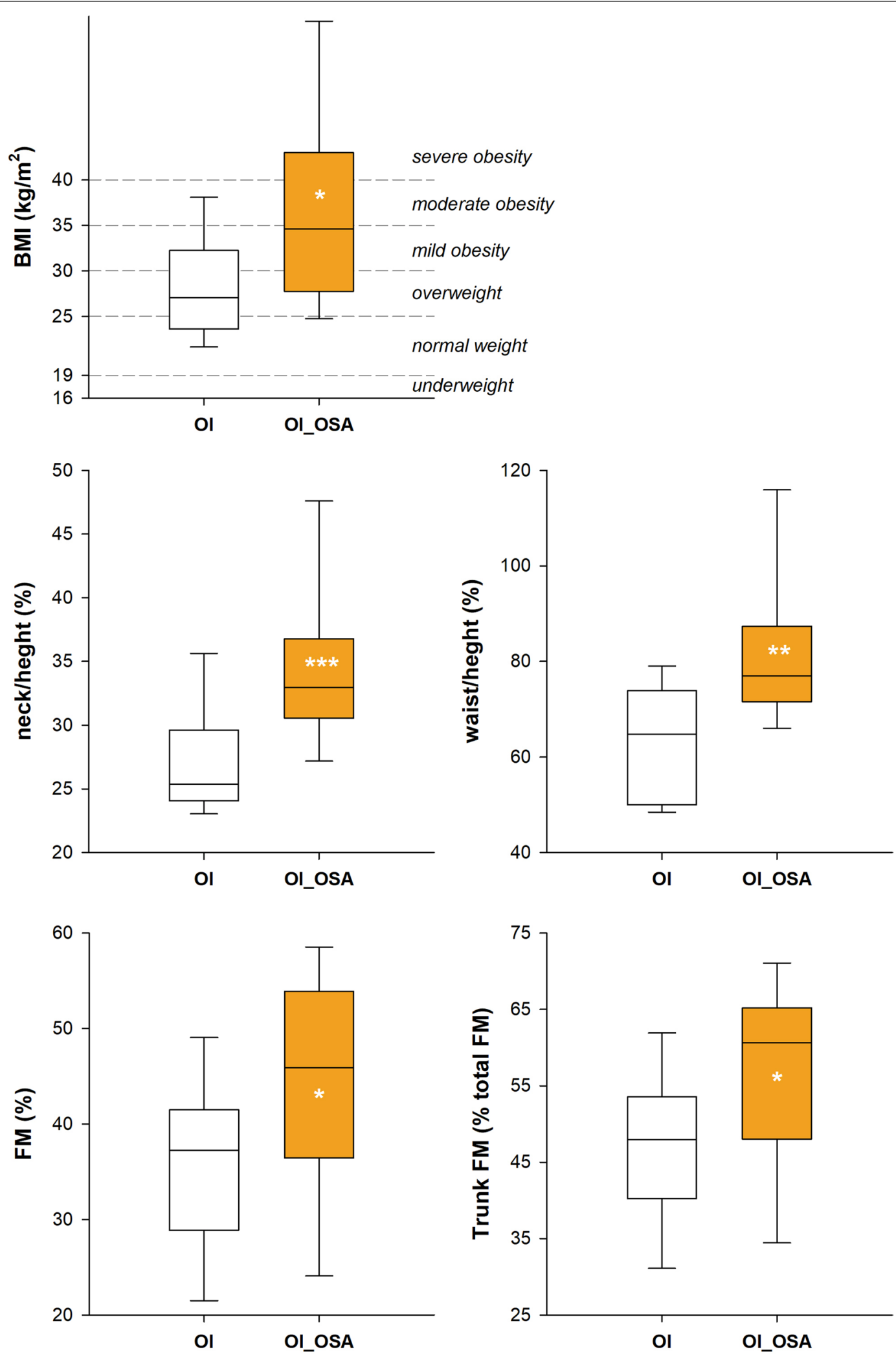

Fig. 6 (See legend on next page.) 
(See figure on previous page.)

Fig. 6 Box-plot representing the median (line within the box), the 10th (whisker below the box), 25th (boundary of the box closest to zero), the 75th (boundary of the box farthest from zero) and the 90th (whisker above the box) percentiles of body mass index (top left), neck circumference to height ratio (middle left), waist circumference to height ratio (middle right), total percentage of fat mass (bottom left) and the percentage of trunk fat mass (bottom right) in patients with (OI_OSA, yellow) and without (OI, white) obstructive sleep apnea. ${ }^{*} p<0.05 ;{ }^{* *} p<0.01 ;{ }^{* * *} p<0.001$

counteracted the expected low quality of life and higher fatigue [50, 51], but they are also in line with the crosssectional questionnaire study by Arponen and colleagues [41]. Such difference between physical severity (assessed by physical function) and subjective severity perception (assessed by general health perception) in OIers was recently pointed out by another author [52]. OI patients, therefore, may perceive their physical disorders and limitations differently from health care professionals. We can speculate the higher pain and fatigue thresholds to be one possible cause of OSA to be underestimated in these patients. For this reason, we strongly recommend nocturnal oxygen saturation to be systematically tested, particularly in patients affected by the severe form of the disease who are overweight/obese, with a particularly important neck circumference and who are expected to paradoxically breathing in supine positon.

To our knowledge, this is the first study investigating the nutritional status, body composition and dietary habits in adult OIers. It is also the only one to simultaneously consider three vital functions (nutrition, breathing and sleeping) that have an important impact on the quality of life. Indeed, other authors have separately investigated sleep [12, 13, 41, 44] or respiratory impairment [6-11] or nutrition [17-19, 46, 47]. The latter was shown to negatively impact the psychosocial wellbeing in the OI population and to limit daily physical activity [53]. Our results put in evidence that OI is not only a bonerelated disease, but it has also important implications on other disciplines due to its intrinsic characteristics. These results suggest that experts in breathing, in sleep and in nutrition must be part of the multidisciplinary team that should follow an OI patient, particularly in the most severe form $[54,55]$.

The study has also some limitations. The orthopaedic implants were manually and carefully removed during the analysis of DXA images analysed with the manufacturer software. The increased use of these medical devices in OIers, however, could lead to an incorrect estimation of the body composition results. We used a self-reported questionnaire on the Mediterranean diet as the first simplest way to analyse the dietary pattern of these patients. Of course, the questionnaire may under- or overestimate the perception of the subject. It does concentrate only on some selected dietary aspects without considering the cumulative and interactive effects among dietary components, which reflect the complexity of the human diet. However, this is the reference questionnaire for the Mediterranean diet and it investigates the frequency of consumption of both the protective and less protective foods in many obesity-correlated pathologies [56]. This questionnaire was validated on other pathologies and it was proved to be less time-consuming and cheaper while requiring low patients' collaboration compared to other more complex methods [57].

The relative low number of patients might be another shortcoming of the study. However, OI is a rare disease and, even if the exact incidence of types III and IV OI is not known, the incidence is much less common than all OI types. In addition, the systematic paradoxical breathing movement and the OSA incidence found were in line with those published on other groups of Olers $[8,12,13$, 41], therefore reinforcing the robustness and the clinical relevance of our results. The physical function was not tested, but it was recently proved to be markedly deteriorated during adulthood, with mobility being significantly

Table 2 Area under the curve (AUC) and threshold that corresponds to the optimal operating point $(T)$ of the ROC analysis

\begin{tabular}{|c|c|c|}
\hline & AUC & $\mathrm{T}$ \\
\hline AHI (events/hours) & 0.97 & 10.50 \\
\hline ODI (events/hour) & 0.93 & 10.00 \\
\hline Mean $\mathrm{SpO}_{2}(\%)$ & 0.05 & 97.20 \\
\hline Nadir $\mathrm{SpO}_{2}(\%)$ & 0.13 & 93.00 \\
\hline $\mathrm{FVC}(\mathrm{L})$ & 0.21 & 4.02 \\
\hline FVC (\%) & 0.15 & 85.17 \\
\hline $\mathrm{FEV}_{1}(\mathrm{~L})$ & 0.19 & 3.56 \\
\hline $\mathrm{FEV}_{1}(\%)$ & 0.21 & 78.55 \\
\hline TLC (L) & 0.24 & 4.72 \\
\hline TLC (\%) & 0.10 & 124.0 \\
\hline$\Delta V_{R C}$ supine (\%) & 0.93 & -6.16 \\
\hline$\Phi_{\text {TA }}$ supine $\left(^{\circ}\right)$ & 0.83 & -126.5 \\
\hline RSBi seated (1/L min) & 0.77 & 126.9 \\
\hline$V_{T}$ seated $(L)$ & 0.28 & 0.44 \\
\hline$\Delta V_{R C}$ seated $(\%)$ & 0.18 & 100.0 \\
\hline BMI $\left(\mathrm{kg} / \mathrm{m}^{2}\right)$ & 0.75 & 34.60 \\
\hline Waist circumference $(\mathrm{cm})$ & 0.72 & 82.80 \\
\hline Neck circumference $(\mathrm{cm})$ & 0.79 & 38.20 \\
\hline Waist/height & 0.84 & 70.65 \\
\hline Neck/height & 0.88 & 31.64 \\
\hline FM (\%) & 0.69 & 43.00 \\
\hline Trunk FM (\%) & 0.74 & 54.83 \\
\hline
\end{tabular}




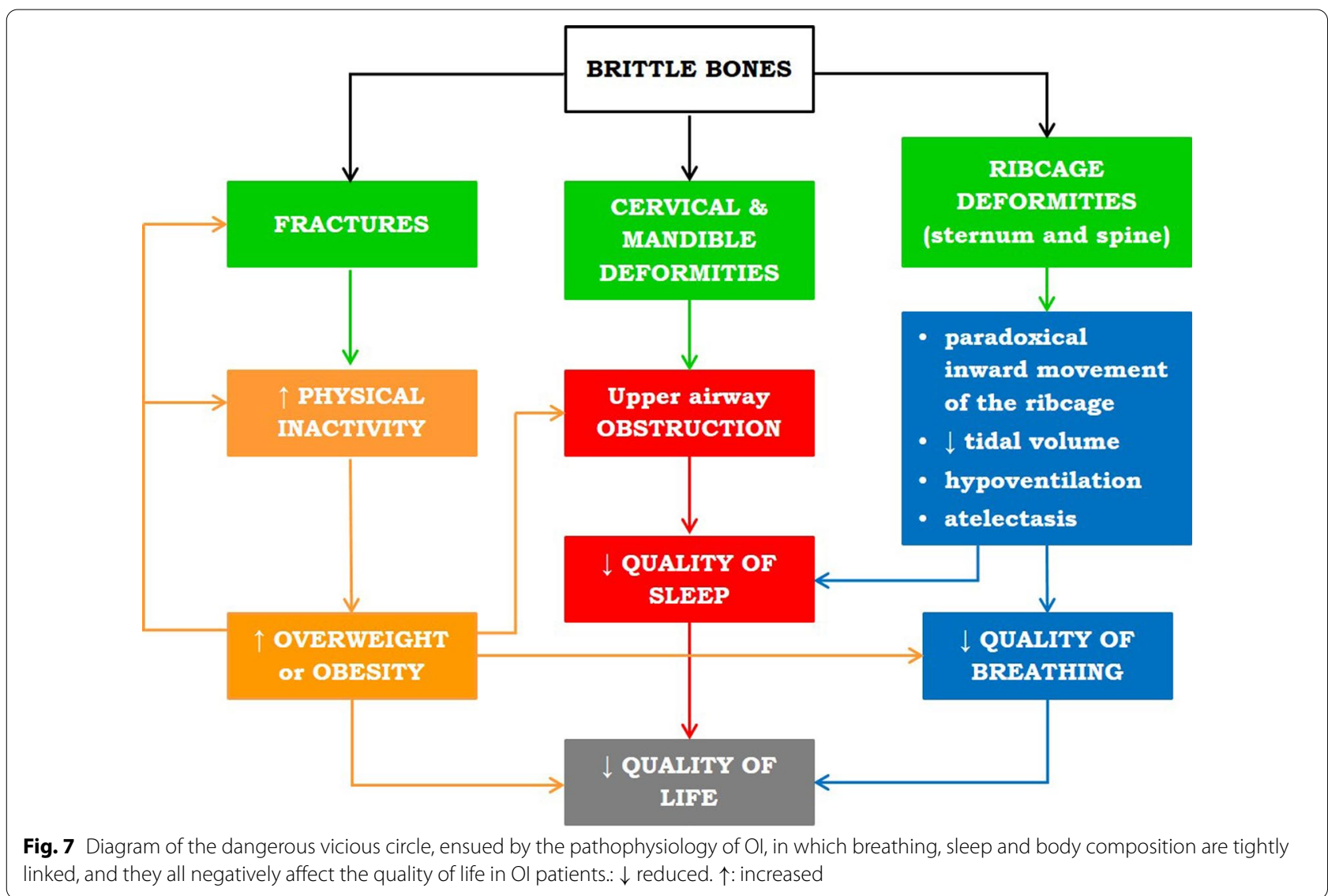

different across the types particularly in type III [45]. We have not verified the presence of cranial, cervical and/or mandibular deformities, a recurrent craniofacial alterations in OI, which can predispose toward an anatomically unfavourable upper airway collapse during sleep [58]. Cheung and collaborators have shown that skull base abnormalities is strongly predicted by the clinical severity of OI with an incidence of $22 \%$ [59]. The way patients were recruited might be a bias in the selection of the population. Because of their physical condition and limitation, Olers might experience also isolation and negative emotions stemming from a feeling of being different [60]. We can speculate that the patients answering to our social call were more prone to maintain a "fighter" attitude and emotions' management. This would also explain the good levels of their answers to the quality of life questionnaire. However, when these patients were asked to score their relationship with food, including food choice and motives, dieting, eating relating problems and body perception, they denied answering. Paradoxically, the BES questionnaire was more informative for the non-answering of patients (rather than for the results per se), as this might reveal an altered psychological pathway related to eating patterns to be investigated [61]. Finally, the observational nature of the study offered no proofs about the linkage between breathing, sleeping, and nutrition in OI patients and whether one may lead to the others or vice versa.

Future interventional studies are urged not only to investigate such linkages, but also the potential role of nNIV and of changes of diet in alleviating breathing problems and physical well-being in these patients. These are crucial points that need to be studied remembering that in OI a combination of some intrinsic characteristics of the disease (i.e. thoracic, cranial and mandibular deformities) and some daily habits of the patients (i.e. physical inactivity and low dietary quality) coexists. While the latter can be changed, the former progressively worsen in the most severe forms. It would be also crucial to verify the adherence to nNIV of these patients, as Fig. 8 showed that it had short-lasting effects in reversing paradoxical breathing. If it is not daily used, the effect of nNIV might be therefore misleading.

\section{Conclusions}

This was the first multidisciplinary study that considers breathing, sleeping and nutritional aspects in the most severe forms of Osteogenesis Imperfecta during adulthood. It pointed out that a dangerous vicious cycle 


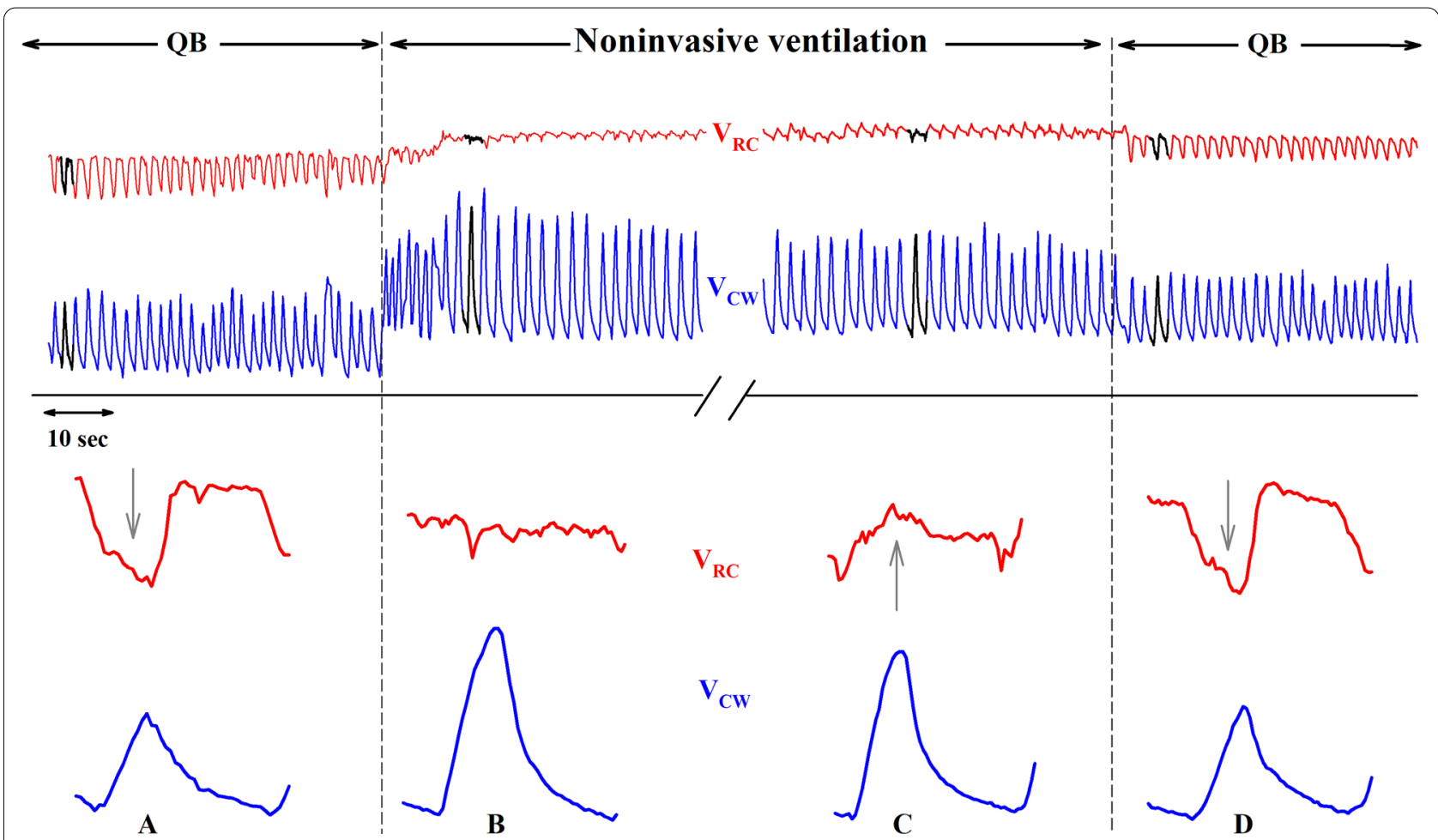

Fig. 8 Volume variations of the ribcage $\left(V_{R C}\right)$ and total chest wall $\left(V_{C W}\right)$ in an Ol type III patient during one minute of spontaneous quite breathing (QB) followed by five minutes of noninvasive ventilation and again one minute of spontaneous breathing after switching off the ventilator (top two tracings). The single breaths indicated by thick lines in the top tracings are shown zoomed in the bottom panels. Data recorded in supine position. Note the presence of an inspiratory paradoxical inward motion of RC during $\mathrm{QB}(\mathbf{A})$, its reduction immediately after the connection to the ventilator (B), the in-phase inspiratory expansion of RC after about 5 min of connection to the ventilator $(\mathbf{C})$ and the reappearance of the paradoxical motion of RC immediately after the switching off the ventilator (D)

ensued among these three functions because of some intrinsic characteristics of the disease and some daily habits of the patients. These bad habits might be partially due to patients' emotional influence on food choice and self-perception, but also to the lack of guidelines on the physical activity and diet appropriate for Olers. The main consequence is a high incidence of obstructive sleep apnoea, which remains an underdiagnosed disorder in individuals with severe OI who are obese, with a neck to height ratio over than $31.6 \%$, and characterized by paradoxical inspiratory thoracic movement in supine position. The combination of nocturnal non-invasive ventilation associated with controlled dietary regime may break the vicious circle therefore improving the wellbeing of these patients because "one cannot breathe well, think well, love well, sleep well, if one has not dined well" (adapted from Virginia Wolf).

\section{Abbreviations}

AHI: Apnea-hypopnea index; AUC: Area under the receiver operating characteristic curve; $\mathrm{BH}$ : Body height; BMC: Bone mineral content; BMI: Body mass index; BW: Body weight; DEXA: Duel-energy X-ray absorptiometry; FEV Forced expiratory volume in the first second; FFM: Fat free mass; LMI: Lean mass index; FM: Fat mass; FMl: Fat mass index; FVC: Forced vital capacity; LM: Lean body mass; MED: Mediterranean; nNIV: Nocturnal non-invasive mechanical ventilation; no_OSA: Patients not developing obstructive sleep apnea; ODI: Oxygen desaturation index; Ol: Osteogensis Imperfecta; OIQoL: Osteogenesis Imperfecta specific quality of life questionnaire; OI_OSA: Patients developing obstructive sleep apnea; OSA: Obstructive sleep apnea; ROC: Receiver operating characteristic; TLC: Total lung capacity; $\triangle V_{R C}$ : Ribcage contribution to tidal volume.

\section{Acknowledgements}

Special thanks go to the patients who volunteered to be part of the project; to Leonardo Panzeri for the precious logistic organization; to A.N.A. Sezione di Lecco for the support; to Giorgio Locarini, Giacomo Leo and Davide Lacca for their help in the preliminary analysis of the data and to Giulia de Carlo, Amalia Bruno and Alice Delledonne for their help in data acquisition.

\section{Authors' contributions}

Conceived and designed the study: ALM; breathing evaluation: ALM and AA; sleep evaluation: CVL and FM; functional and clinical evaluation: PF; nutritional evaluation: SB and RDA. Data analysis and drafting of the manuscript: ALM and RDA. All authors discussed the results and commented on the manuscript and approved its final version.

\section{Funding}

The project was funded by Care4BrittleBones and by As.It.O.I.

\section{Availability of data and materials}

The data that support the findings of this study are available on request from the corresponding author ALM. The data are not publicly available due to 
restrictions, since their containing information that could compromise the privacy of research participants.

\section{Declarations}

\section{Ethics approval and consent to participate}

The study was conducted according to the statement of the Declaration of Helsinki and approved by the Ethical Board Committee of Valduce Hospital - Villa Beretta Rehabilitation Centre, Lecco, Italy. All patients or parents gave their informed consent to participate.

\section{Consent for publication}

All the subjects in Fig. 1 have given their written consent for the publication of identifiable details (i.e. photographs).

\section{Competing interests}

The authors have no conflict of interest to declare.

\section{Author details}

'Dipartimento di Elettronica, Informazione e Bioingegneria, Politecnico di Milano, Piazza Leonardo Da Vinci, 20133 Milano, Italy. ${ }^{2}$ Valduce Hospital - Villa Beretta Rehabilitation Centre, Lecco, Italy. ${ }^{3}$ IRCCS "Eugenio Medea" - Rehabilitation Unit, Bosisio Parini (LC), Italy. ${ }^{4}$ International Center for the Assessment of Nutritional Status (ICANS), Department of Food, Environmental and Nutritional Sciences (DeFENS), University of Milan, Milan, Italy. ${ }^{5}$ Obesity Unit and Laboratory of Nutrition and Obesity Research, Department of Endocrine and Metabolic Diseases, IRCCS Istituto Auxologico Italiano, Milan, Italy.

Received: 21 June 2021 Accepted: 30 September 2021 Published online: 18 October 2021

\section{References}

1. Subramanian S, Viswanathan VK. Osteogenesis Imperfecta. StatPearls. 2021 [cited 2021 Jun 1].

2. Rauch F, Glorieux FH. Osteogenesis imperfecta. Lancet. 2004;363:1377-85.

3. Van Dijk FS, Pals G, Van Rijn RR, Nikkels PGJ, Cobben JM. Classification of Osteogenesis imperfecta revisited. Eur J Med Genet. 2010;53:1-5.

4. McAllion SJ, Paterson CR. Causes of death in osteogenesis imperfecta. J Clin Pathol. 1996;49:627-30.

5. Paterson CR, Ogston SA, Henry RM. Life expectancy in osteogenesis imperfecta. BMJ. 1996;312:351.

6. Falvo KA, Klain DB, Krauss AN, Root L, Auld PA. Pulmonary function studies in osteogenesis imperfecta. Am Rev Respir Dis. 1973;108:1258-60.

7. Widmann RF, Bitan FD, Laplaza FJ, Burke SW, DiMaio MF, Schneider R. Spinal deformity, pulmonary compromise, and quality of life in osteogenesis imperfecta. Spine (Phila Pa 1976). 1999:24:1673-8.

8. LoMauro A, Pochintesta S, Romei M, D’Angelo MG, Pedotti A, Turconi AC, et al. Rib cage deformities alter respiratory muscle action and chest wall function in patients with severe osteogenesis imperfecta. PLoS ONE. 2012;7:e35965.

9. Tam A, Chen S, Schauer E, Grafe I, Bandi V, Shapiro JR, et al. A multicenter study to evaluate pulmonary function in osteogenesis imperfecta. Clin Genet. 2018;94:502-11.

10. LoMauro A, Fraschini P, Pochintesta S, Romei M, D'Angelo MG, Aliverti A. Ribcage deformity and the altered breathing pattern in children with osteogenesis imperfecta. Pediatr Pulmonol. 2018;53:964-72.

11. Sanchis-Gimeno JA, Lois-Zlolniski S, María González-Ruiz J, Palancar CA, Torres-Tamayo N, García-Martínez D, et al. Association between ribs shape and pulmonary function in patients with osteogenesis imperfecta. J Adv Res. 2020;21:177-85.

12. Arponen H, Bachour A, Bäck L, Valta H, Mäkitie A, Waltimo-Sirén J, et al. Is sleep apnea underdiagnosed in adult patients with osteogenesis imperfecta? A single-center cross-sectional study. Orphanet J Rare Dis. 2018;13:1-8.

13. Arponen H, Bachour A, Bäck L, Valta H, Mäkitie A, Mäkitie O, et al. Positive airway pressure therapy for obstructive sleep apnea in patients with osteogenesis imperfecta: a prospective pilot study. BMC Musculoskelet Disord. 2021:22:1-8.
14. Aguiar IC, Freitas WR, Santos IR, Apostolico N, Nacif SR, Urbano JJ, et al. Obstructive sleep apnea and pulmonary function in patients with severe obesity before and after bariatric surgery: a randomized clinical trial. Multidiscip Respir Med. 2014;9:1-9.

15. Sharma B, Feinsilver S, Owens RL, Malhotra A, McSharry D, Karbowitz S. Obstructive airway disease and obstructive sleep apnea: effect of pulmonary function. Lung. 2011;189:37-41.

16. Nahmias J, Kirschner M, Karetzky M. Weight loss and OSA and pulmonary function in obesity. N J Med. 1993;90(1):48-53.

17. Gilani M, Shepherd S, Nichols B, Gerasimidis K, Choong Wong S, Mason A. Evaluation of body composition in paediatric osteogenesis imperfecta. J Clin Densitom. 2021. https://doi.org/10.1016/j.jocd.2021.01.012.

18. Chagas CEA, Roque JP, Santarosa Emo Peters B, Lazaretti-Castro M, Martini LA. Do patients with osteogenesis imperfecta need individualized nutritional support? Nutrition. 2012;28:138-42.

19. Palomo T, Glorieux FH, Schoenau E, Rauch F. Body composition in children and adolescents with osteogenesis imperfecta. J Pediatr. 2016;169:232-7.

20. Sheu Y, Cauley JA. The role of bone marrow and visceral fat on bone metabolism. Curr Osteoporos Rep. 2011:9:67-75.

21. Cao JJ. Effects of obesity on bone metabolism. J Orthop Surg Res. 2011;6:1-7.

22. Pillar G, Shehadeh N. Abdominal fat and sleep apnea: the chicken or the egg? Diabetes Care Am Diabetes Assoc. 2008;31:S303-9.

23. Veilleux L, Trejo P, Rauch F. Muscle abnormalities in osteogenesis imperfecta. J Musculoskelet Neuronal Interact. 2017;17(2):1-7.

24. Hill CL, Baird WO, Walters SJ. Quality of life in children and adolescents with osteogenesis imperfecta: a qualitative interview based study. Health Qual Life Outcomes. 2014;12:1-9.

25. Hill C, Waird W, Walters S. Development of an osteogenesis imperfecta (OI) specific quality of life measure (OIQoL). Physiotherapy. 2016;102(Suppl):e10-1.

26. Whittle MW, Evans M. Instrument for measuring the cobb angle in scoliosis. Lancet. 1979;313:414.

27. Langensiepen S, Semler O, Sobottke R, Fricke O, Franklin J, Schönau E, et al. Measuring procedures to determine the Cobb angle in idiopathic scoliosis: a systematic review. Eur Spine J. 2013;22:2360-71.

28. Mitterling T, Högl B, Schönwald SV, Hackner H, Gabelia D, Biermayr $M$, et al. Sleep and respiration in 100 healthy Caucasian sleepers: a polysomnographic study according to American Academy of Sleep Medicine standards. Sleep. 2015;38:867-75.

29. Lohman T, Roche A, Martorell R. Anthropometric standardization reference manual. Champaign: Human Kinetics Books; 1998.

30. Stults-Kolehmainen MA, Stanforth PR, Bartholomew JB, Lu T, Abolt CJ, Sinha R. DXA estimates of fat in abdominal, trunk and hip regions varies by ethnicity in men. Nutr Diabetes. 2013;3:e64-e64.

31. Schröder H, Fitó M, Estruch R, Martínez-González MA, Corella D, Salas-Salvadó J, et al. A Short screener is valid for assessing mediterranean diet adherence among older spanish men and women. J Nutr. 2011;141:1140-5.

32. De Amicis R, Galasso L, Leone A, Vignati L, De Carlo G, Foppiani A, et al. Is abdominal fat distribution associated with chronotype in adults independently of lifestyle factors? Nutrients. 2020;12:592.

33. Bertoli S, Leone A, Vignati L, Bedogni G, Martínez-González MÁ, BesRastrollo M, et al. Adherence to the Mediterranean diet is inversely associated with visceral abdominal tissue in Caucasian subjects. Clin Nutr. 2015;34:1266-72.

34. Cotter EW, Kelly NR. Binge eating scale (BES). In: Wade T, editor. Encycl feed eat disord. Singapore: Springer; 2016. p. 1-5. https://doi.org/10. 1007/978-981-287-087-2 9-2.

35. Hanley JA, MCNeil BJ. The meaning and use of the area under a receiver operating characteristic (ROC) curve. Radiology. 1982;143:29-36.

36. Swets JA. ROC analysis applied to the evaluation of medical imaging techniques. Invest Radiol. 1979;14:109-21.

37. Sillence DO, Barlow KK, Cole WG, Dietrich S, Garber AP, Rimoin DL. Osteogenesis imperfecta type III. Delineation of the phenotype with reference to genetic heterogeneity. Am J Med Genet. 1986;23:821-32.

38. Sillence DO, Senn A, Danks DM. Genetic heterogeneity in osteogenesis imperfecta. J Med Genet. 1979;16:101-16.

39. Harding SM. Complications and consequences of obstructive sleep apnea. Curr Opin Pulm Med. 2000;6:485-9. 
40. Mulgrew AT, Ryan CF, Fleetham JA, Cheema R, Fox N, Koehoorn M, et al. The impact of obstructive sleep apnea and daytime sleepiness on work limitation. Sleep Med. 2007;9:42-53.

41. Arponen H, Waltimo-Sirén J, Valta H, Mäkitie O. Fatigue and disturbances of sleep in patients with osteogenesis imperfecta: a cross-sectional questionnaire study. BMC Musculoskelet Disord. 2018;19:1-7.

42. Romero-Corral A, Caples SM, Lopez-Jimenez F, Somers VK. Interactions between obesity and obstructive sleep apnea: implications for treatment. Chest. 2010;137:711-9.

43. Thiele F, Cohrs C, Flor A, Lisse T, Przemeck G, Horsch M, et al. Cardiopulmonary dysfunction in the osteogenesis imperfecta mouse model Aga2 and human patients are caused by bone-independent mechanisms. Hum Mol Genet. 2012;21:3535-45.

44. Léotard A, Taytard J, Aouate M, Boule M, Forin V, Lallemant-Dudek P. Diagnosis, follow-up and management of sleep-disordered breathing in children with osteogenesis imperfecta. Ann Phys Rehabil Med. 2018;61:135-9.

45. Orlando G, Pinedo-Villanueva R, Reeves ND, Javaid MK, Ireland A. Physical function in UK adults with osteogenesis imperfecta: a cross-sectional analysis of the RUDY study. Osteoporos Int. 2021:32:157-64.

46. Zambrano MB, Brizola ES, Refosco L, Giugliani R, Félix TM. Anthropometry, nutritional status, and dietary intake in pediatric patients with osteogenesis imperfecta. J Am Coll Nutr. 2014;33:18-25.

47. Zambrano MB, Félix TM, Mello ED. Calcium intake improvement after nutritional intervention in paediatric patients with osteogenesis imperfecta. J Hum Nutr Diet. 2019;32:619-24.

48. Savanelli MC, Barrea L, Macchia PE, Savastano S, Falco A, Renzullo A, et al. Preliminary results demonstrating the impact of Mediterranean diet on bone health. J Transl Med. 2017;15:1-8.

49. Papandreou C, Schiza SE, Bouloukaki I, Hatzis CM, Kafatos AG, Siafakas NM, et al. Effect of Mediterranean diet versus prudent diet combined with physical activity on OSAS: a randomised trial. Eur Respir J. 2012;39:1398-404.

50. Harsevoort AGJ, Gooijer K, Van Dijk FS, Van Der Grijn DAFM, Franken AAM, Dommisse AMV, et al. Fatigue in adults with osteogenesis imperfecta. BMC Musculoskelet Disord. 2020;21:1-6.

51. Dahan-Oliel N, Oliel S, Tsimicalis A, Montpetit K, Rauch F, Dogba MJ. Quality of life in osteogenesis imperfecta: a mixed-methods systematic review. Am J Med Genet Part A. 2016;170:62-76.
52. Gooijer K, Harsevoort AGJ, van Dijk FS, Withaar H, Janus GJM, Franken AAM. A baseline measurement of quality of life in 322 adults with osteogenesis imperfecta. JBMR Plus. 2020;4:e10416.

53. Yonko EA, Emanuel JS, Carter EM, Sandhaus RA, Raggio CL. Respiratory impairment impacts QOL in osteogenesis imperfecta independent of skeletal abnormalities. Arch Osteoporos. 2020;15:1-7.

54. Marr C, Seasman A, Bishop N. Managing the patient with osteogenesis imperfecta: a multidisciplinary approach. J Multidiscip Healthc. 2017:10:145-55.

55. Chougui K, Addab S, Palomo T, Morin SN, Veilleux LN, Bernstein M, et al. Clinical manifestations of osteogenesis imperfecta in adulthood: an integrative review of quantitative studies and case reports. Am J Med Genet A. 2020;182:842-65.

56. Agnoli C, Pounis G, Krogh V. Dietary pattern analysis. In: Pounis G, editor Analysis in nutrition research: principles of statistical methodology and interpretation of the results. Cambridge: Academic Press; 2019. p. 75-101.

57. Martínez-González M, Marcía-Arellano A, Toledo E, Salas-Salvadó J, BuilCosiales P, Corella D, et al. A 14-item Mediterranean diet assessment tool and obesity indexes among high-risk subjects: the PREDIMED trial. PLoS ONE. 2012;7:e43134.

58. Aihara K, Oga T, Harada Y, Chihara Y, Handa T, Tanizawa K, et al. Analysis of anatomical and functional determinants of obstructive sleep apnea. Sleep Breath. 2012;16:473-81.

59. Cheung MS, Arponen H, Roughley P, Azouz ME, Glorieux FH, WaltimoSirén J, et al. Cranial base abnormalities in osteogenesis imperfecta: phenotypic and genotypic determinants. J Bone Miner Res. 2011;26:405-13.

60. Tsimicalis A, Denis-Larocque G, Michalovic A, Lepage C, Williams K, Yao $T R$, et al. The psychosocial experience of individuals living with osteogenesis imperfecta: a mixed-methods systematic review. Qual Life Res. 2016;25:1877-96

61. Leigh GE. Emotional influences on food choice: sensory, physiological and psychological pathways. Physiol Behav. 2006;89:53-61.

\section{Publisher's Note}

Springer Nature remains neutral with regard to jurisdictional claims in published maps and institutional affiliations.
Ready to submit your research? Choose BMC and benefit from:

- fast, convenient online submission

- thorough peer review by experienced researchers in your field

- rapid publication on acceptance

- support for research data, including large and complex data types

- gold Open Access which fosters wider collaboration and increased citations

- maximum visibility for your research: over $100 \mathrm{M}$ website views per year

At BMC, research is always in progress.

Learn more biomedcentral.com/submissions 